\title{
Asynchronous Motor Parameter Identification Based on Vector Control
}

\author{
Dao Zhang ${ }^{1}$ and Tao Huang, ${ }^{2, *}$ \\ ${ }^{1}$ Key Laboratory of Fiber Optic Sensing Technology and Information Processing (Wuhan University of Technology), Ministry of \\ Education, School of Information Engineering, Wuhan, China \\ ${ }^{2}$ Key Laboratory of Fiber Optic Sensing Technology and Information Processing (Wuhan University of Technology), Ministry of \\ Education, School of Information Engineering, Wuhan, China \\ ${ }^{*}$ Corresponding author
}

\begin{abstract}
In the three-phase asynchronous motor vector control system, the internal parameters of the motor will directly affect the performance of vector control. Using the existing resources of the voltage type inverter speed regulation system of induction motor, the DC test, the no-load test and the singlephase AC experiment of the motor are used to input different excitation signals to the motor to detect the voltage and current response of the motor, and the stator resistance, Stator and rotor mutual inductance, stator resistance and stator and rotor leakage inductance. Combined with the theory, using MATLAB /SIMULINK tools to build the simulation model to identify the relevant parameters of the motor, and finally use the identified parameters to build three-phase AC induction motor vector control system simulation. The results show that the control system has good speed performance.
\end{abstract}

Keywords-asynchronous motor; vector control; parameter identification; matlab/simulink simulation

\section{INTRODUCTION}

Commonly used in asynchronous motor control strategy is the vector control and direct torque control. However, the control performance of these two control methods is greatly affected by the parameters inside the motor itself. If the motor parameters are out of tune, especially the rotor time constant and mutual inductance, the driving performance of the motor will be largely deteriorated[1].Under normal circumstances, the inverter and asynchronous motors are provided by different manufacturers in the variable frequency speed regulation system of asysnchronous motors. Generally, the manufacturers of asynchronous motors do not mark the parameters such as the stator resistance and leakage inductance of the motor in the motor nameplate[2]. And then the asynchronous motor parameter identification method came into being. Motor parameter identification is divided into two kinds of offline identification and online identification, online identification of the current model reference adaptive and least squares method, these methods are not easy to achieve[3,4].The traditional measurement methods of asynchronous motor parameters are short-circuit test and no-load test[5]. However, in many cases, it is not suitable for short-circuit test and no-load test. The article introduces a new method of asynchronous parameter identification of induction motor, which does not need other hardware devices. By applying different excitation signals to the motor and observing the motor response, various parameters can be calculated.

\section{RELATED WORK}

The use of voltage-type inverter circuit speed control system, the motor injection of different frequency excitation signal to identify the motor parameters. Voltage type inverter circuit shown in Figure I.

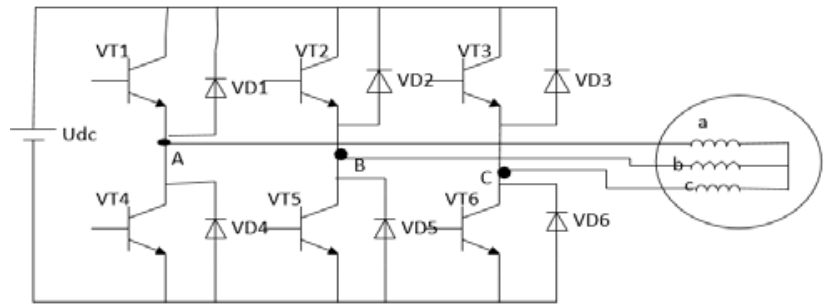

FIGURE I. VOLTAGE-TYPE INVERTER SPEED CONTROL SYSTEM

Asynchronous motor parameters offline identification need the following experiments: DC experiment, single-phase experiment, no-load test[6].Among them, DC experiment identifies motor stator resistance, single-phase experiment identifies motor rotor resistance and stator rotor leakage inductance, and no-load test identifies motor mutual inductance.

\section{PROPOSED WORK}

\section{A. Stator Resistance Identification}

Under normal circumstances, generally considered threephase asynchronous motor stator resistance equal to identify the basic principle of stator resistance is the DC voltammetry[7].The concrete realization is as follows: Let the VT1, VT4 and VT6 tubes in the inverter shown in figure 1 be in the on state, and the VT2, VT3 and VT5 are in the off state. When the DC voltage is injected from the A phase and the inductance is equivalent to the short circuit, the $\mathrm{T}$ type equivalent circuit becomes as shown in Figure II. 


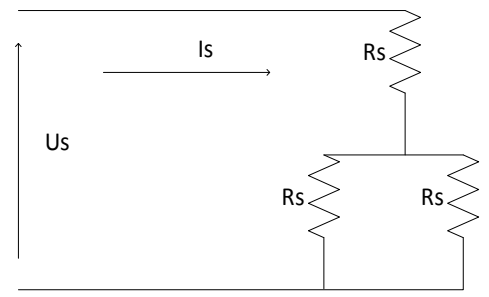

FIGURE II. DC EQUIVALENT CIRCUIT

Figure II shows the stator resistance:

$$
\mathrm{Rs}=U s / 1.5^{*} I_{s}
$$

Simulation:

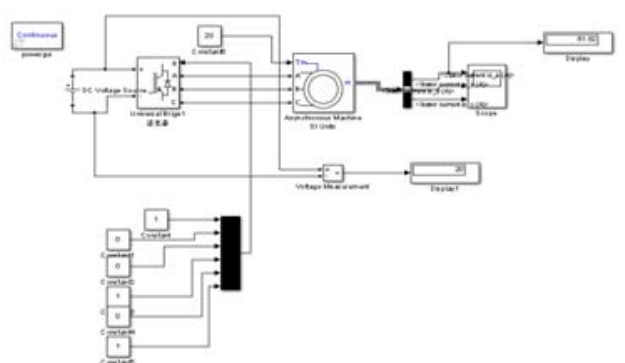

FIGURE III. STATOR RESISTANCE IDENTIFICATION SIMULATION MODEL

\section{B. Rotor resistance and Stator Rotor Leakage Inductance Identification}

It is assumed that the stator leakage inductance is the same as the rotor leakage inductance[8]. By analyzing the T-type equivalent circuit of the motor, it is found that as long as any two phases of the stator are short-circuited and the high frequency voltage signal is injected, the motor stalling condition can be simulated. Of course, cannot really wire any two phases of the stator shorted together here to achieve B, C two-phase short circuit is to make B, C two-phase control signals are the same. When the high-frequency AC voltage is injected into the A phase, the AC induction motor is in the blocked state. Considering the large mutual inductance $\mathrm{Lm}$, the current flowing through the excitation circuit is negligible. The applied voltage basically landed on the stator resistance and leakage inductance. The equivalent circuit is shown in Figure IV.

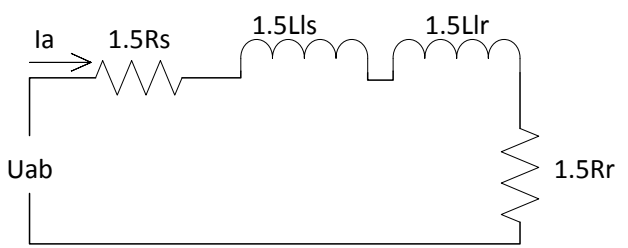

FIGURE IV. SINGLE-PHASE EQUIVALENT CIRCUIT

From Figure IV we can see, equivalent impedance $\mathrm{Z}$, equivalent resistance $\mathrm{R}$, equivalent reactance $\mathrm{X} 1$ respectively.

$$
\left.\begin{array}{l}
Z=U_{a b} / I_{a} \\
\mathrm{R}=\frac{\mathrm{U}_{\mathrm{ab}}}{\mathrm{I}_{\mathrm{a}}} * \cos \theta \\
\mathrm{X}_{1}=\frac{\mathrm{U}_{\mathrm{ab}}}{\mathrm{I}_{\mathrm{a}}} * \sin \theta
\end{array}\right\}
$$

The stator and rotor leakage inductance are as follows:

$$
\text { Lls }=L l r=\frac{X_{1}}{3 * \omega}=\frac{U_{a b}}{3 * I_{a} * \omega} * \sin (\theta)
$$

Where $\omega$ is the voltage fundamental frequency.

Rotor resistance is ${ }^{[9]}$ :

$$
\mathrm{R}_{r}=\frac{2}{3} R-R_{s}=\frac{2}{3} \frac{U_{a b}}{I a} * \cos (\theta)-R_{s}
$$

The concrete realization process is: Use SVPWM control algorithm, from $U$ a the input single-phase high-frequency voltage, $\mathrm{U} \beta=0$, to ensure that $\mathrm{B}, \mathrm{C}$ two-phase control signal is the same, to achieve $\mathrm{B}, \mathrm{C}$ shorted, when the current is stable, the A phase current and voltage between $\mathrm{A}$ and $\mathrm{B}[10]$, Through the Fourier transform, the RMS value of the fundamental wave and the phase difference of the voltage and current are obtained, and the rotor resistance of the motor and its stator and rotor leakage inductance are calculated according to formulas (3) and (4).

Simulation Shown in Figure V:

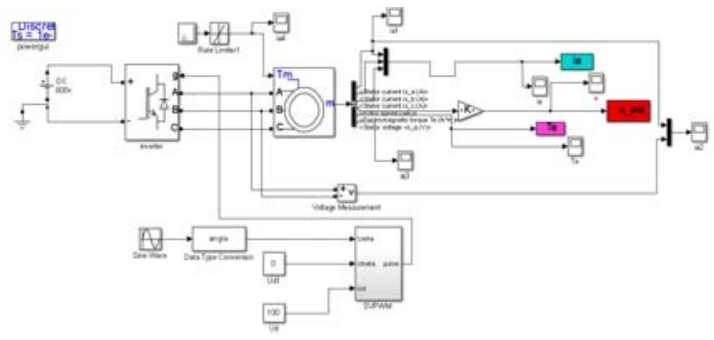

FIGURE V. SINGLE-PHASE EXPERIMENTAL SIMULATION MODEL

\section{Mutual Inductance Lm Identification}

The machine mutual inductance of asynchronous motor is obtained through no-load experiment, through V / f control, the motor speed is close to the synchronous speed, the slip $\mathrm{s} \approx 0$, the stator current is basically equal to the excitation current, the motor rotor circuit is equivalent to an open circuit. The equivalent circuit is shown in Figure VI. V/ f control block diagram shown in Figure VII, where $\mathrm{f}$ is the motor rated frequency. 


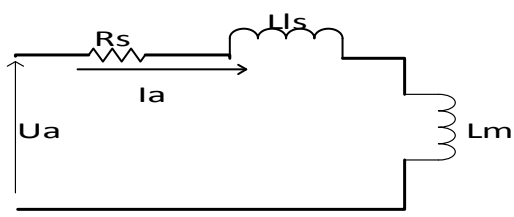

FIGURE VI. NO-LOAD TEST EQUIVALENT CIRCUIT DIAGRAM

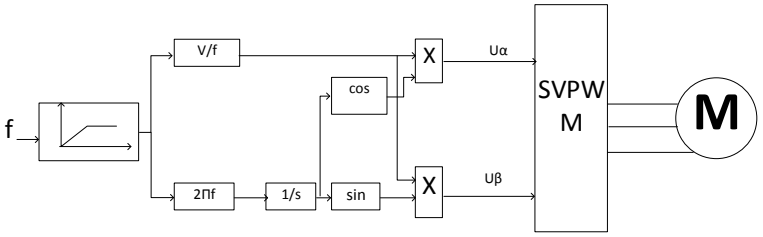

FIGURE VII. NO-LOAD TEST V / F CONTROL BLOCK DIAGRAM

After the speed is stable, the phase voltage and phase current of the motor are detected, and the effective value of the voltage and current and the phase difference are obtained through the Fourier transform. Mutual inductance can be calculated according to formula (6).The equivalent reactance in Figure VI is:

$$
X_{2}=\left(U_{a} / I_{a}\right) * \sin (\theta)
$$

Mutual inductance is:

$$
\mathrm{Lm}=\mathrm{X}_{2} / 2 \pi f-L l s
$$

\section{SIMULATION RESULT ANALYSIS}

In order to verify the accuracy of the offline identification method of the motor parameters mentioned in the paper, the system was simulated by MATLAB / Simulink platform, The selected motor rated parameters of the simulation model are: rated voltage $400 \mathrm{~V}$, rated frequency $50 \mathrm{~Hz}$, rated speed 1460r / min, rated power $15 \mathrm{KW}$. Motor parameters: rotor resistance Rs $=0.2147 \Omega$, stator resistance $\mathrm{Rr}=0.2205 \Omega$, stator leakage inductance $\mathrm{Lls}=\mathrm{Llr}=0.000991 \mathrm{H}$, mutual inductance $\mathrm{Lm}=$ $0.06419 \mathrm{H}$.

\section{A. DC Experimental Simulation}

DC simulation waveform shown in Figure VIII.

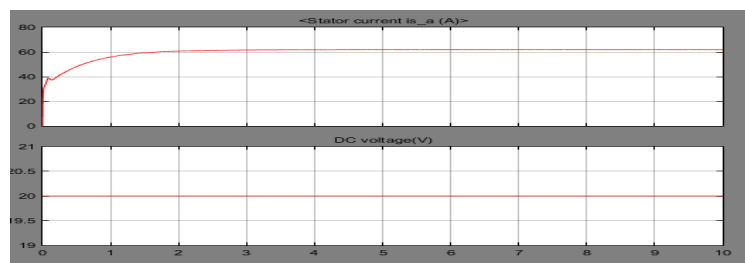

FIGURE VIII. DC EXPERIMENTAL SIMULATION

It can be seen from the waveform DC voltage Us $=20 \mathrm{~V}, \mathrm{~A}$ phase current Is stable current value is $61.82 \mathrm{~A}$, calculate the value of resistance $\mathrm{Rs}=0.2157 \Omega$.

\section{B. Single-Phase Experiment Simulation}

Figure IX is a single-phase experiment simulation of the voltage and current waveforms. After the Fourier transform voltage Uab RMS is $259.8 \mathrm{~V}$, the effective value of the current Ia is $13.35 \mathrm{~A}$, and the phase difference of the voltage and current is $\theta=268.1$. Calculated $\mathrm{Rr}=0.21095 \Omega$. $\mathrm{L} 1 \mathrm{~s}=\mathrm{Llr}=0.0009827 \mathrm{H}$. (The Fourier transform here is implemented using simulink powergui.)

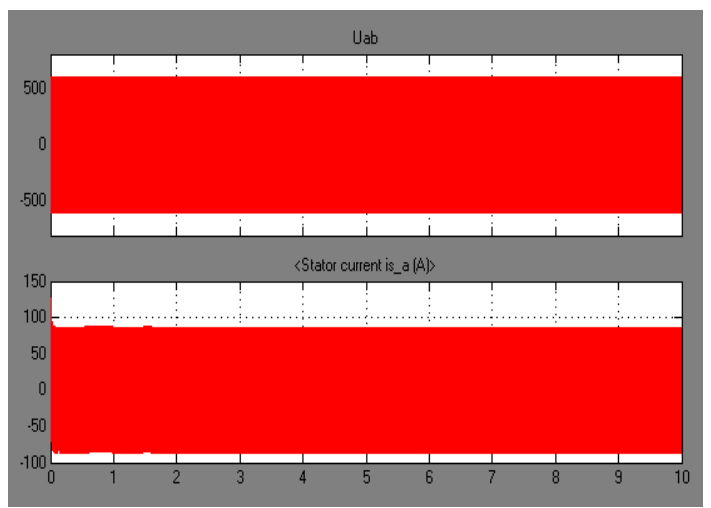

FIGURE IX. SINGLE-PHASE EXPERIMENTAL VOLTAGE AND CURRENT WAVEFORMS

\section{No-load Test Simulation}

Figure $\mathrm{X}$ is a no-load experiment simulation of the voltage and current waveforms, After the Fourier transform voltage Ua RMS is $243.9 \mathrm{~V}$, the effective value of the current Ia is $12.22 \mathrm{~A}$, and the phase difference of the voltage and current is $\theta=72.9^{\circ}$. Calculated $\mathrm{Lm}=0.05975 \mathrm{H}$.

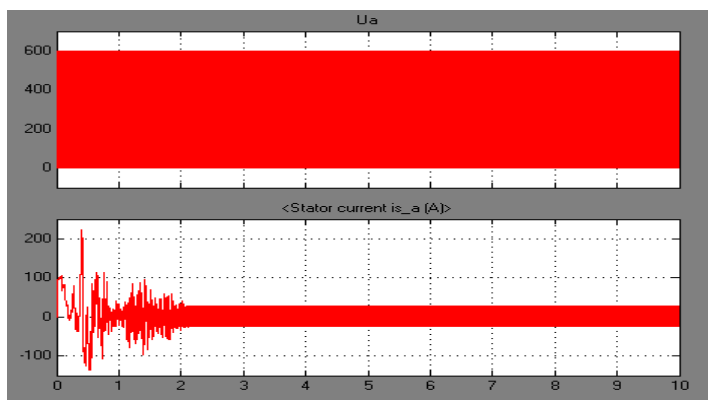

FIGURE X. NO-LOAD TEST VOLTAGE AND CURRENT WAVEFORMS

\section{Parameter Comparison Results}

TABLE I. IDENTIFICATION PARAMETERS COMPARISON TABLE

\begin{tabular}{|l|l|c|c|}
\hline $\begin{array}{c}\text { Moto } \\
\text { r } \\
\text { para } \\
\text { mete } \\
\text { rs }\end{array}$ & \multicolumn{3}{|c|}{ value } \\
\cline { 2 - 4 } & Actual value & Identification value & error \\
\hline $\mathrm{Rs}$ & 0.2147 & 0.2157 & $0.46 \%$ \\
\hline $\mathrm{Rr}$ & 0.2205 & 0.2110 & $4.35 \%$ \\
\hline $\mathrm{Lls}$ & 0.000991 & 0.000983 & $0.81 \%$ \\
\hline $\mathrm{Llr}$ & 0.000991 & 0.000983 & $0.81 \%$ \\
\hline $\mathrm{Lm}$ & 0.06419 & 0.05975 & $6.91 \%$ \\
\hline
\end{tabular}




\section{VECTOR CONTROL SIMULATION}

The model is run twice, the model calculation parameters for the first time the actual parameters of the motor, and the second is to identify the parameters, the two waveforms shown in Figure XI and Figure XII.

Calculate module which contains the coordinate transformation and flux estimation. Figure 11 is the vector control of the actual parameters of the motor output speed, Figure 12 is the identification of vector control speed output parameters. The first given speed is $900 \mathrm{r} / \mathrm{min}$, at $\mathrm{t}=0.2 \mathrm{~s}$ will be given the speed increased to $940 \mathrm{r} / \mathrm{min}$. The load torque is added at $0.25 \mathrm{~s}$, the speed can be obviously reduced by the partial enlargement, but the speed is restored to the given speed at once, which achieves good speed regulation performance. Comparing the actual parameters with the motor speed output of the identification parameters, it can be seen that the identification parameters can also accurately achieve the speed regulation performance of the motor vector control.

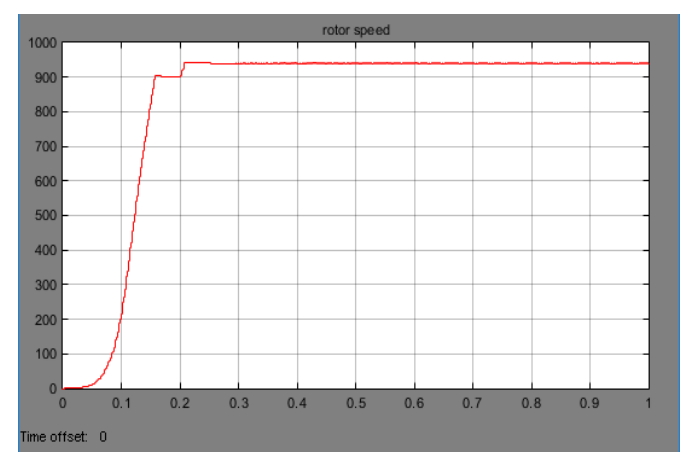

(a) Actual parameter vector control result

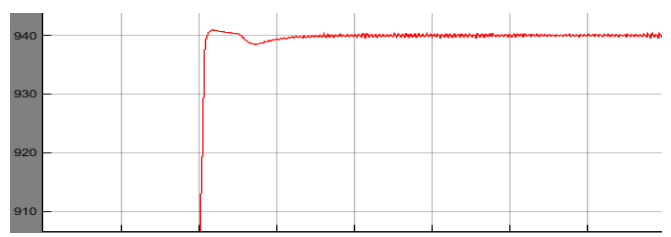

(b) A partial enlargement

FIGURE XI. ACTUAL PARAMETER VECTOR CONTROL RESULT

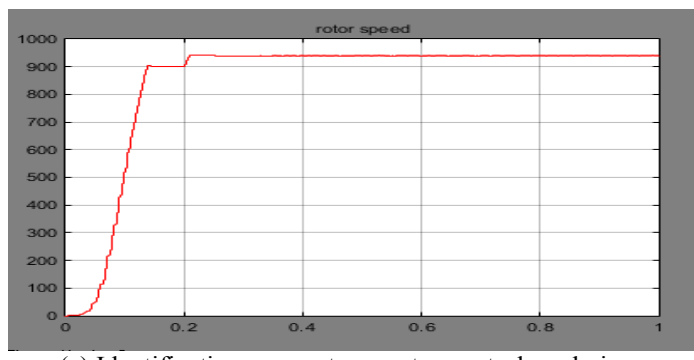

(a) Identification parameters vector control renderings

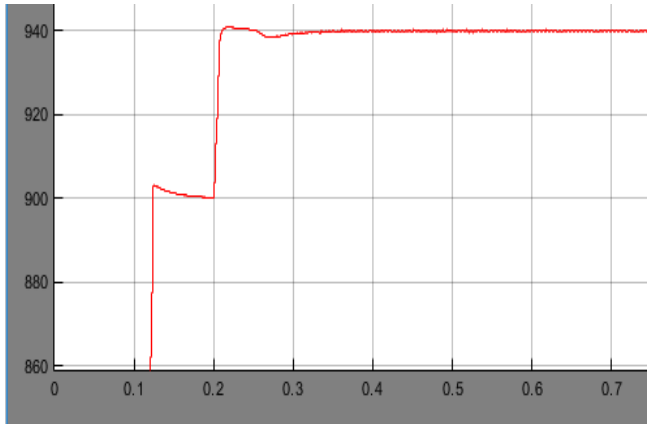

(b) A partial enlargement

FIGURE XII. IDENTIFICATION PARAMETERS VECTOR CONTROL RENDERINGS

\section{CONCLUSION}

In this paper, an offline parameter identification method of asynchronous motor is studied. The parameters of induction motor are identified respectively by DC experiment, singlephase experiment and no-load experiment. The simulation results show that it is advisable to use it within the permissible error range. The identification accuracy of the stator resistance and the stator rotor leakage inductance is higher than that of the rotor resistance and the mutual inductance. Therefore, it is necessary to pay attention to the slight change of the parameters during the operation of the motor and appropriate compensation should be given [11].

\section{REFERENCES}

[1] Novotny D W, Lipo T A.Vector Control and Dynamics of AC Drives[M]. Clarendon Press Oxford,1996

[2] Wei He. Detection and Parameter Identification of Induction Motor Vector Control[M]. Nanchang: University of Nanchang,2013

[3] Xia Zhou. Induction Motor Parameter Identification Based on Model Reference Adaptive System [M].Zhejiang: University of Zhejiang,2011

[4] Bing Han. Asynchronous Motor Parameter Identification and Hardware in the loop Simulation for Vector Control [M]. Wuhan: Wuhan University of Technology, 2013

[5] Xiaolon Wang. Research on AC Induction Motor Parameter Identification [M].Jilin: University of Jilin, 2015

[6] Min Li,Bing Xiao.Asynchronous motor parameter identification [J].Information Technology,2013,5:104-110

[7] Liang Dai,Asynchronous Motor Offline Parameter Identification Method at Rest [J]. Design and analysis, 2014, 42(2): 33-36

[8] Toliyat H A,Levi E,Raina M.A review of RFO induction motor parameter estimation techniques[J].IEEE Transactions on EnergyConversion,2003,18(2) : 271-283.

[9] Huynh DC, Dunnigan M, Finney S. On -line parameter estimation of an induction machine using a recursiveleast-squares algorithm with multiple time-varyingforgetting factors[C].Power and Energy (PECon), 2010 IEEE International Conference on, 2010: 444-449. 
[10] Kaiyu Wang, John Chiasson, Marc Bodson. A nonlinear least-squares approach for identification of the induction motor parameters [J]. IEEE Transcationson Automatic Control, 2005, 50 (10): 1622-1628.

[11] Amar Bentounsi, Hind Djeghloud, Hocine Benalla. Computer -aided teaching using Matlab/Simulink for enhancing an IM course with laboratory tests [J].IEEE Transcations on Education,2011,54 (3): 479491. 